\title{
Depression in Feed Intake by a Highly Fermentable Diet Is Related to Plasma Insulin Concentration and Insulin Response to Glucose Infusion ${ }^{1}$
}

\author{
B. J. Bradford ${ }^{2}$ and M. S. Allen ${ }^{3}$ \\ Department of Animal Science, Michigan State University, East Lansing 48824
}

\begin{abstract}
The effects of dietary starch fermentability on feed intake and nutrient digestibility were evaluated in a crossover study, which was also designed to find factors that predict individual variation in feed intake response to starch fermentability. Thirty-two multiparous Holstein cows $(121 \pm 48 \mathrm{~d}$ in milk, $44 \pm 7 \mathrm{~kg} / \mathrm{d}$ of milk yield; mean $\pm \mathrm{SD}$ ) were randomly assigned to treatment sequence and were fed a diet intermediate to the treatments during a preliminary 28-d period. Treatments were dry ground corn grain and high-moisture corn harvested from the same field. Treatment periods were $14 \mathrm{~d}$, with the final $4 \mathrm{~d}$ used for data and sample collection. Diets included corn silage and alfalfa haylage at a $2: 1$ ratio and were $26 \%$ neutral detergent fiber, $17 \%$ crude protein, $32 \%$ starch, and $3.5 \%$ fatty acids. Highmoisture corn decreased dry matter intake (DMI) by $8 \%$, but did not significantly alter digestible DMI. Individual DMI responses were highly variable, and variables from preliminary plasma analyses, propionate challenge tests, glucose tolerance tests, and hepatic mRNA analysis were assessed as potential predictors of DMI response to increased dietary starch fermentability. Of the covariates tested, only preliminary plasma insulin concentration and insulin response to glucose infusion were significant predictors of DMI response. High preliminary plasma insulin concentration was correlated with greater depression in DMI with increased fermentability; conversely, greater insulin secretion in response to glucose infusion was associated with minimal depression in DMI. These insulin variables were not significantly correlated. Consistent with
\end{abstract}

\footnotetext{
Received February 6, 2007.

Accepted April 10, 2007.

${ }^{1}$ This material is based on work supported by the Cooperative State Research, Education, and Extension Service, USDA, under Agreement No. 2004-35206-14167, and under a National Science Foundation Graduate Research Fellowship.

${ }^{2}$ Current address: 127 Call Hall, Kansas State University, Manhattan, KS 66506

${ }^{3}$ Corresponding author: allenm@msu.edu
}

past results, increased dietary starch fermentability decreased DMI. Significant correlations between insulin variables and individual DMI responses may warrant further investigation.

Key words: dairy cattle, starch digestibility, feed intake, glucose tolerance test

\section{INTRODUCTION}

High-producing dairy cows require large amounts of dietary energy to meet requirements for maintenance, milk synthesis, and reproduction. In the United States, these energy requirements are often met by adding corn grain to the diet. Although corn grain in general is a highly digestible energy source, its ruminal fermentability may vary greatly because of differences in preservation method. Several studies have shown increases in ruminal starch digestibility of 19 to $24 \%$ for high-moisture corn diets (HM) relative to ground dry corn diets (DG; Knowlton et al., 1998; Ying et al., 1998; Oba and Allen, 2003b). These large differences in starch fermentability are expected to result in very different rates of propionate production and absorption. Although propionate is the primary glucose precursor in dairy cattle, it may also serve as the primary metabolic limitation to feed intake (Allen, 2000). Ruminal infusions of propionate decreased ME intake in lactating dairy cows relative to iso-osmotic infusions of acetate (Oba and Allen, 2003d).

Oba and Allen (2003a) compared a HM diet with a DG diet, both including approximately $32 \%$ starch. The HM diet caused a $1.7 \mathrm{~kg} / \mathrm{d}$ depression in DMI relative to the DG diet without affecting the mean or variance of ruminal $\mathrm{pH}$. However, responses to the change in starch fermentability were highly variable across cows. Individual responses to propionate infusion are also highly variable. Oba and Allen (2003c) reported that these responses were predicted by plasma glucose concentration; cows with the greatest plasma glucose concentrations responded to propionate infusion with the greatest depression in feed intake. This finding led us to the hypothesis that such predictors may be found for 
individual responses to starch fermentability as well, because enhanced propionate production is likely the cause of feed intake depression when starch fermentability is increased. The objective of this experiment was to determine whether individual intake responses to a change in starch fermentability could be predicted by production or metabolic variables.

\section{MATERIALS AND METHODS}

Experimental procedures were approved by the AllUniversity Committee on Animal Use and Care at Michigan State University. Milk production and plasma metabolite and hormone data for this experiment were reported previously (Bradford and Allen, 2004).

\section{Design and Treatments}

Thirty-two multiparous Holstein cows (121 \pm 48 DIM; mean \pm SD) from the Michigan State University Dairy Cattle Teaching and Research Center were assigned randomly to sequence in a crossover experiment with a preliminary period. At the beginning of the experiment, BW of cows was $675 \pm 69 \mathrm{~kg}$ and FCM yield was 41.3 $\pm 9.6 \mathrm{~kg} / \mathrm{d}$ (mean $\pm \mathrm{SD}$ ). All cows were fed a single diet intermediate in composition to the 2 treatment diets for $28 \mathrm{~d}$ in a preliminary (PRE) period. This PRE period was added to obtain baseline values for DMI, milk yield, plasma metabolites and hormones, and hepatic transcript abundance, and to conduct glucose tolerance tests (GTT) and propionate challenge tests (PCT), all independent of dietary treatments. A number of these variables were measured during the preliminary period only to assess their predictive value and were not measured during the treatment periods.

Treatment periods were $14 \mathrm{~d}$, with the final $4 \mathrm{~d}$ of each period used to collect samples and data; the length of the entire experiment was $56 \mathrm{~d}$. Treatments were conservation method of corn grain (HM vs. DG). One corn hybrid (Great Lakes 4526; Great Lakes Hybrids, Ovid, MI) was grown in 2002, and half of the field was harvested as $\mathrm{HM}$ at $69 \% \mathrm{DM}$, ground, and ensiled in a $2.4 \times 30.0 \mathrm{~m}$ silage bag (Ag Bagger, Ag Bag Corp., Blair, $\mathrm{NE}$ ). The remaining half of the field was harvested as DG at $83 \%$ DM, dried to $86 \%$ DM by a forced-air dryer, and finely ground. Experimental diets contained either HM or DG, corn silage (67\% of forage DM), alfalfa silage (33\% of forage $\mathrm{DM}$ ), a premix of protein supplements, a premix of minerals and vitamins, and liquid urea supplement (Table 1). All diets were formulated for $18 \%$ dietary CP (DM basis) and fed as a TMR.
Table 1. Ingredients and nutrient composition of experimental $\operatorname{diets}^{1}$

\begin{tabular}{lrrr}
\hline Item $^{2}$ & PRE & DG & HM \\
\hline Diet ingredient & & & \\
Dry ground corn grain & 14.7 & 30.3 & - \\
High-moisture corn grain & 15.8 & - & 32.1 \\
Alfalfa haylage & 15.4 & 14.9 & 14.5 \\
Corn silage & 30.7 & 30.8 & 30.0 \\
Protein mix & 15.2 & 15.6 & 15.2 \\
Mineral and vitamin mix & 5.3 & 5.4 & 5.3 \\
Liquid urea supplement & 2.9 & 3.0 & 2.9 \\
Nutrient composition & & & \\
DM & 46.1 & 49.1 & 47.8 \\
OM & 93.3 & 93.5 & 93.6 \\
Starch & 31.5 & 31.7 & 32.8 \\
NDF & 25.1 & 26.2 & 25.3 \\
Indigestible NDF & 7.0 & 6.8 & 6.7 \\
CP & 15.3 & 16.5 & 16.3 \\
\hline
\end{tabular}

${ }^{1} \mathrm{PRE}$ = intermediate preliminary diet; $\mathrm{DG}=$ dry ground corn diet; $\mathrm{HM}=$ high-moisture corn diet. Values other than DM are expressed as a percentage of dietary DM.

${ }^{2}$ The protein mix contained $75 \%$ soybean meal, $20 \%$ blood meal, and 5\% SoyPlus (West Central Soy, Ralston, IA) on a DM basis. The mineral and vitamin mix contained $58.5 \% \mathrm{DG}, 17.0 \%$ limestone, $10.5 \%$ dicalcium phosphate, $7.9 \%$ sodium bicarbonate, $2.1 \%$ magnesium oxide, $1.7 \%$ trace mineral premix, $1.6 \%$ trace mineral salt, and $0.8 \%$ vitamin $\mathrm{A}, \mathrm{D}$, and $\mathrm{E}$ premix. The liquid urea supplement was QLF Dairy TMR 20 (Quality Liquid Feeds, Dodgeville, WI). Indigestible NDF was estimated after $120 \mathrm{~h}$ of in vitro ruminal fermentation.

\section{Data and Sample Collection}

Throughout the experiment, cows were housed in tie stalls, fed once daily (1000 h) at $115 \%$ of expected intake, and milked twice daily in a milking parlor. One cow was removed from the experiment prior to its completion because of health problems unrelated to the experimental treatments. Cows were blocked from feed between $900 \mathrm{~h}$ and $1000 \mathrm{~h}$ daily, and the amount of feed offered and orts were weighed for each cow during collection periods. Samples of all dietary ingredients $(0.5 \mathrm{~kg})$ and orts $(12.5 \%)$ were collected daily and composited into one sample per cow per period. Fecal samples were collected 3 times at 8 -h intervals on d 14 of each experimental period and were composited into one sample per cow period. Body weight and BCS were measured on $d 1$ of each period and at the conclusion of the experiment. Body condition was scored by 3 trained investigators on a 5-point scale, where $1=$ thin and $5=$ fat, as described by Wildman et al. (1982).

Blood samples were collected every $9 \mathrm{~h}$ during $\mathrm{d} 12$ to 14 of the PRE period to represent every $3 \mathrm{~h}$ of a 24 $\mathrm{h}$ period. Blood was sampled from coccygeal vessels and collected into 2 evacuated tubes, one containing potassium EDTA and the other containing potassium oxalate with sodium fluoride as a glycolytic inhibitor. Both were centrifuged at $2,000 \times g$ for 15 min immediately after sample collection, and plasma was harvested and frozen at $-20^{\circ} \mathrm{C}$ until analysis. Samples containing 
$\mathrm{K}_{3}$ EDTA were preserved with benzamidine $(0.05 M$ final concentration).

GTT and PCT. Beginning on d 19 of the PRE period, GTT and PCT were conducted. Infusion tests were administered to blocks of 16 cows on each day; blocks corresponded to treatment sequence in the crossover portion of the experiment. All cows were fitted with a single jugular catheter $2 \mathrm{~d}$ prior to the GTT. Indwelling polypropylene catheters $(0.24 \mathrm{~cm}$ o.d. $\times 0.17 \mathrm{~cm}$ i.d. tubing, MRE 095, Braintree Scientific, Braintree, MA) were inserted through a 10-gauge needle until approximately $30 \mathrm{~cm}$ of tubing was inside the jugular vein. Catheter patency was checked daily throughout the experiment. On the day of the GTT, cows were blocked from feed at $800 \mathrm{~h}$ and were not allowed access until GTT were completed. Sterile solutions of $50 \%$ dextrose (wt/vol) were administered by intrajugular bolus at a dose of $1.67 \mathrm{mmol}$ glucose $/ \mathrm{kg}$ of BW over the course of 5 to $10 \mathrm{~min}$. Plasma samples were collected from the jugular vein 10 min prior to infusion, immediately before infusion, and every $10 \mathrm{~min}$ through $120 \mathrm{~min}$ postinfusion. All time points denoted are relative to the beginning of infusion. Catheters were flushed with $5 \mathrm{~mL}$ of sterile $4.2 \% \mathrm{Na}$ citrate after infusion and after each blood sample collection. Propionate challenge tests were conducted after 1 or $2 \mathrm{~d}$ of rest. Sodium propionate (USP grade, Spectrum Chemical, New Brunswick, NJ) was dissolved in distilled, deionized water at a concentration of $4.5 \mathrm{~mol} / \mathrm{L}$, adjusted to $\mathrm{pH} 7.4$ with $\mathrm{NaOH}$, and filtered (\#4 filter, Whatman International, Maidstone, UK). On test days, Na propionate was infused over a period of 5 to $10 \mathrm{~min}$ at a dose of $1.04 \mathrm{mmol} / \mathrm{kg}$ of BW. Infusion, sampling, and catheter maintenance were completed as for the GTT, and blood samples were processed and stored as described for the tail-bleeding protocol. One catheter was lost during both the GTT and $\mathrm{PCT}$, so 31 response curves were determined for each infusion test.

Liver Biopsies. On d 15 (block 1) and 16 (block 2) of the PRE period, liver biopsies were collected for measurement of transcript abundance for several proteins involved in gluconeogenesis. After local anesthetization with $2 \%$ lidocaine hydrochloride, biopsy instruments (14-gauge Vet-Core biopsy needles, Global Veterinary Products, New Buffalo, MI) were inserted between the 11th and 12th ribs on a line between the olecranon and the tuber coxae on the right side. Ten samples of approximately $20 \mathrm{mg}$ were collected, immediately placed in RNAlater (Ambion Inc., Austin, TX) to inhibit endogenous RNAse activity, and stored at $-80^{\circ} \mathrm{C}$ until further processing.

\section{Sample and Statistical Analysis}

Diet ingredients and orts were dried in a $55^{\circ} \mathrm{C}$ forcedair oven for $72 \mathrm{~h}$ and analyzed for DM concentration. All samples were ground with a Wiley mill (1-mm screen; Arthur H. Thomas, Philadelphia, PA). Samples were analyzed for ash, NDF, indigestible NDF, CP, and starch. Ash concentration was determined after $5 \mathrm{~h}$ of oxidation at $500^{\circ} \mathrm{C}$ in a muffle furnace. Concentrations of NDF were determined (Van Soest et al., 1991, method A). Crude protein was analyzed according to Hach et al. (1987). Starch was measured by an enzymatic method (Karkalas, 1985) after samples were gelatinized with sodium hydroxide; glucose concentration was measured with a glucose oxidase method (Sigma Chemical Co., St. Louis, MO). Indigestible NDF was estimated as NDF residue after $120 \mathrm{~h}$ of in vitro fermentation (Goering and Van Soest, 1970). Ruminal fluid for the in vitro incubations was collected from a nonpregnant dry cow fed alfalfa hay only. Indigestible NDF was used as an internal marker to calculate apparent digestibilities of DM, OM, starch, and NDF (Cochran et al., 1986). Concentrations of all nutrients except for DM were expressed as percentages of DM determined by drying at $105^{\circ} \mathrm{C}$ in a forced-air oven for more than $8 \mathrm{~h}$.

Plasma samples were analyzed using commercial kits to determine the plasma concentrations of glucose (Glucose kit \#510; Sigma Chemical Co.), NEFA (NEFA Ckit, Wako Chemicals USA, Richmond, VA), BHBA (procedure \#2440, Stanbio Laboratory, Boerne, TX), insulin (Coat-A-Count, Diagnostic Products Corporation, Los Angeles, CA), and glucagon (Glucagon kit \#GL-32K, Linco Research Inc., St. Charles, MO). Plasma leptin was analyzed as previously described (Bradford et al., $2006 \mathrm{~b})$. Each assay had a CV of less than $10 \%$.

Transcript Abundance. Ribonucleic acid was isolated from liver samples according to a method modified from Chomczynski and Sacchi (1987). Approximately $40 \mathrm{mg}$ of tissue was homogenized in $1 \mathrm{~mL}$ of Trizol reagent (Invitrogen, Carlsbad, CA), $200 \mu \mathrm{L}$ of chloroform was added to the homogenate, and the mixture was centrifuged. The aqueous layer was collected and $500 \mu \mathrm{L}$ of isopropanol was added to precipitate RNA. Ribonucleic acid isolates were treated with DNAse (Ambion) to remove any DNA contamination, and quality was verified by analysis with an Agilent 2100 Bioanalyzer (Agilent Technologies, Palo Alto, CA).

Messenger RNA abundance for phosphoenolpyruvate carboxykinase (cytosolic form), glucose-6-phosphatase (catalytic subunit), pyruvate carboxylase, and pyruvate dehydrogenase kinase 4 was analyzed by quantitative real-time reverse transcription PCR (qRT-PCR) using a commercial kit (Superscript III Platinum Two-Step qRT-PCR kit, Invitrogen). Reverse transcription was conducted using oligo-dT primers with $1 \mu \mathrm{g}$ of total RNA added as template. Following RNase $\mathrm{H}$ treatment, the cDNA product was quantified by a spectrophotometer. Real-time PCR was carried out in duplicate using 
$1 \mu \mathrm{g}$ of cDNA and was monitored using the ABI Prism 7000 Sequence Detection System (Applied Biosystems, Foster City, CA). Labeled LUX primers (FAM label) and complementary unlabeled primers (Invitrogen) were designed as previously described (Bradford and Allen, 2005). Melting point analysis confirmed that only the transcripts of interest were amplified during PCR. Copy numbers for each gene were measured with 2 separate qRT-PCR analyses using standard curves to allow for absolute quantification (Whelan et al., 2003). Clones used for standards were described previously (Bradford and Allen, 2005). Messenger RNA abundance was normalized using the geometric mean of copy numbers of cyclophilin, $\beta$-actin, and phosphoglycerate kinase 1 in each sample (Vandesompele et al., 2002). These control genes were selected from genes used for normalization in the literature, based on consistent expression patterns in a preliminary study (unpublished data).

Statistical Analysis. Area under the curve was calculated by the trapezoidal rule for infusion test variables by using the mean of the -10 and 0 min time points as the baseline value for each test. Insulin response index was calculated from GTT responses using the ratio of maximum insulin:maximum glucose. Main effects of treatment were analyzed using the fit model procedure of JMP (version 5.0, SAS Institute, Cary, NC) according to the following model:

$$
\mathrm{Y}_{\mathrm{ijkl}}=\mu+\mathrm{P}_{\mathrm{i}}+\mathrm{T}_{\mathrm{j}}+\mathrm{S}_{\mathrm{k}}+\mathrm{C}_{\mathrm{l}}\left(\mathrm{S}_{\mathrm{k}}\right)+\mathrm{e}_{\mathrm{ijk} \mathrm{l}},
$$

where $Y_{i j k l}$ is the dependent variable, $\mu$ is the overall mean, $P_{i}$ is the fixed effect of period ( $i=1$ to 2 ), $T_{j}$ is the fixed effect of treatment ( $\mathrm{j}=1$ to 2 ), $\mathrm{S}_{\mathrm{k}}$ is the fixed effect of treatment sequence ( $\mathrm{k}=1$ to 2$), \mathrm{C}_{\mathrm{l}}\left(\mathrm{S}_{\mathrm{k}}\right)$ is the random effect of cow ( $(=1$ to 16$)$ within sequence, and $\mathrm{e}_{\mathrm{ijkl}}$ is the residual. Residual distributions were visually checked for normality. Treatment effects were declared significant at $P<0.05$, and tendencies for treatment effects were declared at $P<0.10$.

Individual differences in response to treatments were of interest in this study, and regression analyses were used to assess potential predictors of individual response. To quantify the hypophagic effects of increasing dietary starch fermentability, the following formula was used: DMI response = DMI during HM treatment - DMI during DG treatment. There was a significant effect of period on DMI, so the parameter estimate for the period term was added to the DMI response variable for all cows in one sequence and subtracted from all cows in the other sequence. For regression analysis, the distribution of Cook's D statistics was visually checked and outliers were removed from the analysis. No more than 3 data points were removed from any regression,
Table 2. Effects of corn grain conservation method on intake, digestibility, and BW of lactating cows ${ }^{1}$

\begin{tabular}{lcccc}
\hline Item & DG & HM & SEM & $P^{2}$ \\
\hline DMI, kg/d & 25.6 & 23.6 & 0.6 & $<\mathbf{0 . 0 0 1}$ \\
Total-tract digestibility, \% of intake & & & & \\
DM & 74.7 & 77.4 & 0.5 & $<\mathbf{0 . 0 0 1}$ \\
OM & 75.9 & 78.8 & 0.4 & $<\mathbf{0 . 0 0 1}$ \\
Starch & 94.0 & 98.0 & 0.3 & $<\mathbf{0 . 0 0 1}$ \\
NDF & 53.6 & 52.4 & 0.9 & 0.24 \\
DM apparently digested, kg/d & 18.3 & 17.9 & 0.4 & 0.35 \\
BW change, kg/d & 0.34 & 0.40 & 0.19 & 0.81 \\
BCS change, per 14 d & 0.05 & 0.09 & 0.04 & 0.52 \\
\hline
\end{tabular}

${ }^{1}$ Values are least squares means, $\mathrm{n}=31$. DG $=$ dry ground corn diet; HM = high-moisture corn diet.

${ }^{2}$ Values in bold indicate significant treatment effects $(P<0.05$.).

and quadratic regressions were tested for each relationship. To control the experiment-wise type I error rate, significance was declared at $P<0.01$ and tendencies were declared at $P<0.02$ for regression analyses.

\section{RESULTS AND DISCUSSION}

The HM diet depressed DMI relative to the DG diet $(P<0.001$; Table 2). The depression in DMI of $2.0 \mathrm{~kg} /$ $\mathrm{d}$ for the more fermentable diet was similar to the 1.7 $\mathrm{kg} / \mathrm{d}$ depression in DMI observed by Oba and Allen (Oba and Allen, 2003a). However, total-tract starch and DM digestibilities were decreased by DG $(P<0.001)$, and as a result, digestible DMI was not significantly altered by treatment $(P=0.35)$. Consistent with the lack of effect on digestible DMI, neither FCM yield (Bradford and Allen, 2004) nor BCS change differed by treatment (Table 2).

A number of studies have shown increased total-tract starch digestibility with HM relative to DG (Huntington, 1997; Knowlton et al., 1998; Oba and Allen, 2003b). Earlier harvest of HM can result in decreased vitreousness of starch granules and increased digestibility relative to DG (Correa et al., 2002). In addition, ensiling leads to microbial degradation of the protein matrix surrounding starch granules, increasing fermentability of the starch (Kotarski et al., 1992). Differences in ruminal fermentability of HM and DG are typically greater than differences in whole-tract digestibility (Huntington, 1997; Oba and Allen, 2003b), and HM likely caused substantially greater propionate production than the DG treatment in this experiment (Oba and Allen, 2003a).

Several mechanisms have been proposed to explain depression of feed intake by inclusion of highly digestible starch sources in ruminant diets. The NRC (2001) model implicitly identifies energy requirements as the primary factor limiting feed intake. However, McCar- 
thy and coworkers (1989) used barley to increase ruminal starch fermentability compared with corn, and observed a significant decrease in DMI with no increase in DM digestibility; total-tract DM digestibility was unaltered because increased starch fermentability resulted in decreased NDF digestibility. At least in that study, feed intake was not regulated to maintain uniform energy intake. Propionate has been implicated in feed intake regulation in ruminants because portal infusion decreases DMI (Anil and Forbes, 1980), and intraruminal propionate infusion depresses energy intake (Oba and Allen, 2003d) relative to acetate infusions. The expected increase in propionate production by HM in this experiment may have caused the observed decrease in DMI. However, other hypotheses have been advanced that point to reactive oxygen species (Illius et al., 2002) or total energy absorbed as factors limiting feed intake. These hypotheses have a number of shortcomings; there is currently no proposed mechanism by which whole-body oxidative stress can be relayed to the brain to influence satiety or hunger, and models proposing that animals eat to their energy requirements ignore the fact that diet can alter energy requirements (Harvatine and Allen, 2006). Nevertheless, these hypotheses, like the propionate oxidation hypothesis, predict a decrease in DMI with HM. Therefore, our results do not provide strong support for any proposed mechanism of feed intake regulation.

\section{Variability in DMI Responses to Altered Starch Fermentability}

In addition to assessing the effects of dietary starch fermentability across animals, this experiment was designed to find animal characteristics that predict individual DMI response to increased starch fermentability. Individual variability in DMI response was great, ranging from an increase of $0.9 \mathrm{~kg} / \mathrm{d}$ to a decrease of $6.0 \mathrm{~kg} / \mathrm{d}$ when starch fermentability was increased. Dry matter intake response variables were compared with independent PRE variables, including plasma hormone and metabolite concentrations, production characteristics, infusion test responses, and hepatic transcript abundance. Most PRE variables were not related to DMI response; however, significant relationships with 2 insulin variables were observed (Table 3). Plasma insulin concentration during the PRE period was inversely correlated with DMI response $(\mathrm{r}=-0.53, P<$ 0.01 ), indicating that cows with greater plasma insulin concentrations prior to treatment initiation experienced greater depression of DMI when starch fermentability was increased (Figure 1). The insulin response index following glucose infusion was quadratically related to DMI response $\left(\mathrm{r}^{2}=0.40, P<0.01\right.$; Figure
2 ). Over most of the range of the data, cows with a greater insulin secretory response to glucose were better able to maintain feed intake on highly fermentable diets, but this response appeared to level off at approximately $40 \mu \mathrm{IU}$ of insulin/mg of glucose.

High plasma insulin concentrations in the PRE period may be indicative of adequate nutritional status and may provide negative feedback on hepatic gluconeogenesis. This relationship is consistent with our hypothesis that decreased use of propionate for glucose production leads to greater propionate oxidation and decreased DMI (Allen et al., 2005). Individual cows with an adequate supply of glucogenic precursors may respond to a further increase in supply by decreasing DMI. However, the relationship between the GTT insulin response index and DMI response seems to refute this proposed explanation. Cows that responded to increased plasma glucose concentration with greater insulin secretion (at 10 to 20 min postinfusion) were better able to maintain DMI on the more fermentable diet. If negative feedback on gluconeogenesis by insulin were involved in intake depression by HM, an inverse correlation would be expected. However, the multiple, complicated effects of insulin on nutrient homeostasis make this conclusion less clear. It is possible that cows with strong responses to increased plasma glucose concentration are able to clear nutrients from the bloodstream more quickly after meals, potentially decreasing the intermeal interval (Oba and Allen, 2000).

Mean daily plasma insulin concentration and insulin response to glucose infusion are clearly unique measures (correlation: $\mathrm{r}=0.06, P=0.78$ ), lending credence to the idea that mechanisms underlying the respective relationships are different. Although insulin is known to down-regulate transcription of gluconeogenic genes (Barthel and Schmoll, 2003), short-term increases in insulin concentration have little effect on gluconeogenesis; rather, acute effects of insulin on hepatic glucose production are due to decreased glycogenolysis (Cherrington, 1999). If insulin enhances propionate-induced hypophagia by suppressing gluconeogenesis, then chronic elevation may be required to observe its effect. On the other hand, insulin rapidly increases nutrient uptake in peripheral tissues through a number of posttranscriptional mechanisms (Anderson et al., 2005). Therefore, it is reasonable to suggest that amplified insulin response to glucose has greater effects on nutrient clearance than on gluconeogenesis, whereas chronic increases in insulin concentration decrease the gluconeogenic capacity.

Despite indications that measures related to insulin predicted responses to diet fermentability, the status of insulin as a long-term regulator of feed intake in lactating ruminants is questionable. Although strong 
Table 3. Pearson correlation coefficients for DMI response and potential preliminary response predictors ${ }^{1}$

\begin{tabular}{|c|c|c|c|}
\hline Variable & $\mathrm{r}$ & $r^{2}$ & $P$ \\
\hline Milk production $(3.5 \%$ FCM $)$ & 0.24 & 0.06 & 0.19 \\
\hline DIM & -0.25 & 0.06 & 0.17 \\
\hline $\mathrm{BCS}$ & -0.01 & 0.00 & 0.95 \\
\hline Plasma glucose concentration & -0.04 & 0.00 & 0.82 \\
\hline Plasma NEFA concentration & 0.05 & 0.00 & 0.78 \\
\hline Plasma BHBA concentration & -0.17 & 0.03 & 0.37 \\
\hline Plasma insulin concentration & -0.53 & 0.28 & $<0.01$ \\
\hline Plasma glucagon concentration & 0.00 & 0.00 & 0.99 \\
\hline Insulin:glucagon ratio & -0.24 & 0.06 & 0.21 \\
\hline Plasma leptin concentration & -0.10 & 0.01 & 0.62 \\
\hline \multicolumn{4}{|l|}{ Glucose tolerance test } \\
\hline Glucose area under the curve & 0.01 & 0.00 & 0.95 \\
\hline Maximum glucose & -0.36 & 0.13 & 0.06 \\
\hline Insulin area under the curve & 0.45 & 0.20 & 0.03 \\
\hline Maximum insulin & 0.37 & 0.14 & 0.07 \\
\hline Insulin response index ${ }^{2}$ & & 0.40 & $<0.01$ \\
\hline \multicolumn{4}{|l|}{ Propionate challenge test } \\
\hline Glucose area under the curve & -0.13 & 0.02 & 0.49 \\
\hline Maximum glucose & -0.25 & 0.06 & 0.19 \\
\hline Insulin area under the curve & 0.12 & 0.01 & 0.54 \\
\hline Maximum insulin & 0.14 & 0.02 & 0.47 \\
\hline Relative phosphoenolpyruvate carboxykinase mRNA abundance & 0.08 & 0.01 & 0.69 \\
\hline Relative pyruvate carboxylase mRNA abundance & 0.18 & 0.03 & 0.35 \\
\hline Relative glucose-6-phosphatase mRNA abundance & 0.10 & 0.01 & 0.58 \\
\hline Relative pyruvate dehydrogenase kinase 4 mRNA abundance & -0.10 & 0.01 & 0.60 \\
\hline
\end{tabular}

${ }^{1} \mathrm{DMI}$ response data are corrected for differences in treatment sequence. Values in bold indicate significant relationships $(P<0.01)$.

${ }^{2}$ Quadratic relationship.

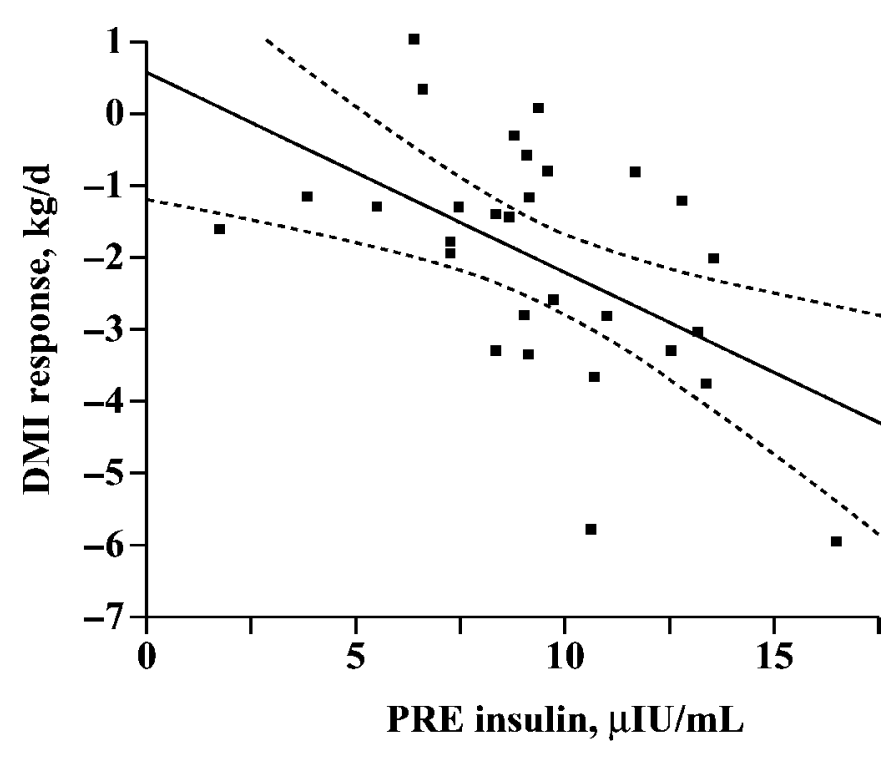

Figure 1. Preliminary plasma insulin concentration (PRE insulin) predicted the DMI response to an increase in dietary starch fermentability. The DMI response was calculated as (HM - DG) DMI (where HM is a high-moisture corn diet and DG is a dry ground corn grain diet), corrected for a period effect. Two outliers were removed prior to the regression analysis. The solid line represents the least squares regression, and the dashed lines show the 95\% confidence interval for the regression. $\mathrm{r}^{2}=0.28, P<0.01, \mathrm{n}=29$. relationships between adiposity and insulin concentrations have been reported in the biomedical literature (Bagdade et al., 1967; Polonsky et al., 1988), the evidence for a similar relationship in lactating dairy cattle is weak. Body condition score measured during the PRE period was highly correlated with plasma leptin concentration (Bradford et al., 2006b), but its correlation with plasma insulin concentration revealed only a tendency for a relationship (Figure 3 ). This and other findings (Meikle et al., 2004) suggest that in mature cows, insulin may not serve as an adiposity signal for long-term control of feed intake. Nevertheless, insulin may interact with absorbed nutrients to affect feed intake through its influences on hepatic metabolism and nutrient partitioning.

There are likely a number of reasons why so few relationships with DMI response were observed. One drawback to the use of dietary treatments is that diet adaptation periods are required; as a result, PRE variables were determined 35 to $42 \mathrm{~d}$ prior to period 2 data collection. Variables such as PRE plasma NEFA concentration or hepatic transcript abundance may have had no relationship with the metabolic state of the cow $42 \mathrm{~d}$ later. The length of the experiment also prevented the use of early-lactation cows, because their responses tend to change dramatically by period; this may have contributed to the lack of a relationship with 


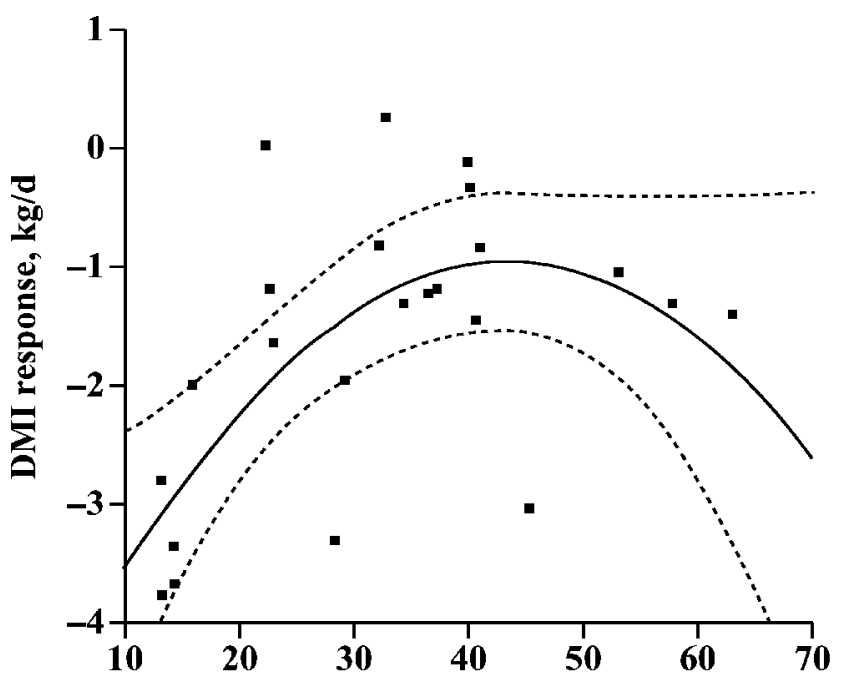

Insulin response index, $\mu \mathrm{IU}$ of insulin/mg of glucose

Figure 2. The insulin response index from glucose tolerance tests (GTT) predicted the DMI response to increased dietary starch fermentability. The DMI response was calculated as (HM - DG) DMI (where HM is a high-moisture corn diet and DG is a dry ground corn grain diet), corrected for a period effect. The insulin response was quantified as the ratio of maximum insulin:maximum glucose. Three outliers were removed prior to the regression analysis; other individuals were not included because of missing GTT time points. The solid line represents the least squares regression, and the dashed lines show the 95\% confidence interval for the regression. $\mathrm{r}^{2}=0.40, P<$ $0.01, \mathrm{n}=23$.

DIM. More surprising, perhaps, is the fact that measures of glucose and insulin responses from the PCT were not related to DMI depression. Oba and Allen (2003c) reported a clear relationship between plasma glucose concentration and DMI response to intraruminal propionate infusion; however, we recently reported that jugular administration of propionate stimulates glycogenolysis, indicating that changes in plasma glucose concentration during the PCT do not exclusively reflect increased gluconeogenesis (Bradford et al., 2006a). In addition, insulin responds to changes in both propionate and glucose concentrations during the PCT, adding noise that may mask differences that were observed during the GTT. The fact that simple measures such as BCS, production level, and plasma glucose concentration did not predict the DMI response suggests that the mechanisms causing intake depression on highly fermentable diets may involve interactions of metabolic factors.

\section{CONCLUSIONS}

Increasing the fermentability of starch in a high-concentrate dairy ration depressed DMI but did not have significant effects on digestible DMI or BW gain. Pre-

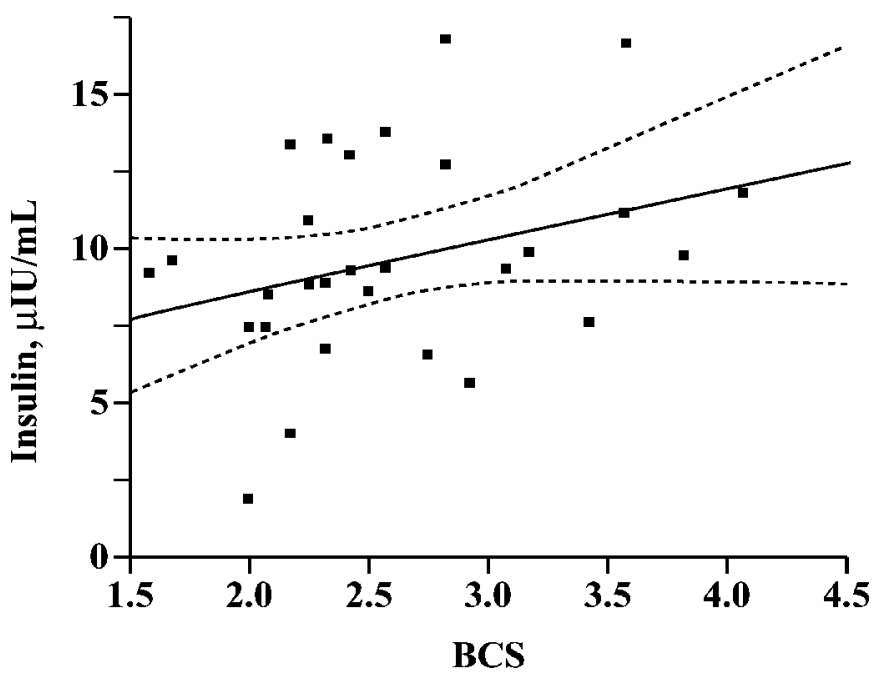

Figure 3. Body condition score was weakly correlated with plasma insulin concentration. Values are from the preliminary (PRE) period, and 2 outliers were removed prior to the regression analysis. The solid line represents the least squares regression, and the dashed lines show the $95 \%$ confidence interval for the regression. $\mathrm{r}^{2}=0.10$, $P<0.10, \mathrm{n}=30$.

liminary plasma insulin concentration was negatively related to DMI response to increasing dietary starch fermentability, whereas insulin response to glucose infusion was correlated with DMI response. A better understanding of the relationship between insulin dynamics and behavioral responses to diet formulation could potentially provide new avenues for targeted feeding of lactating dairy cattle.

\section{ACKNOWLEDGMENTS}

The authors thank R. E. Kreft, D. G. Main, R. A. Longuski, Y. Ying, K. J. Harvatine, C. C. Taylor, C. S. Mooney, and J. A. Voelker Linton for their technical assistance; Y. R. Boisclair and R. A. Ehrhardt for leptin analysis; and West Central Soy (Ralston, IA) for donation of SoyPlus.

\section{REFERENCES}

Allen, M. S. 2000. Effects of diet on short-term regulation of feed intake by lactating dairy cattle. J. Dairy Sci. 83:1598-1624.

Allen, M. S., B. J. Bradford, and K. J. Harvatine. 2005. The cow as a model to study food intake regulation. Annu. Rev. Nutr. 25:523-547.

Anderson, M. S., M. Thamotharan, D. Kao, S. U. Devaskar, L. Qiao, J. E. Friedman, and W. W. Hay Jr. 2005. Effects of acute hyperinsulinemia on insulin signal transduction and glucose transporters in ovine fetal skeletal muscle. Am. J. Physiol. Regul. Integr. Comp. Physiol. 288:R473-R481.

Anil, M. H., and J. M. Forbes. 1980. Feeding in sheep during intraportal infusions of short-chain fatty acids and the effect of liver denervation. J. Physiol. 298:407-414.

Bagdade, J. D., E. L. Bierman, and D. Porte Jr. 1967. The significance of basal insulin levels in the evaluation of the insulin response 
to glucose in diabetic and nondiabetic subjects. J. Clin. Invest. 46:1549-1557.

Barthel, A., and D. Schmoll. 2003. Novel concepts in insulin regulation of hepatic gluconeogenesis. Am. J. Physiol. Endocrinol. Metab. 285:E685-E692.

Bradford, B. J., and M. S. Allen. 2004. Milk fat responses to a change in diet fermentability vary by production level in dairy cattle. J. Dairy Sci. 87:3800-3807.

Bradford, B. J., and M. S. Allen. 2005. Phlorizin administration increases hepatic gluconeogenic enzyme mRNA abundance but not feed intake in late-lactation dairy cows. J. Nutr. 135:2206-2211.

Bradford, B. J., A. D. Gour, A. S. Nash, and M. S. Allen. 2006a. Propionate challenge tests have limited value for investigating bovine metabolism. J. Nutr. 136:1915-1920.

Bradford, B. J., M. Oba, R. A. Ehrhardt, Y. R. Boisclair, and M. S. Allen. 2006b. Propionate is not an important regulator of plasma leptin concentration in dairy cattle. Domest. Anim. Endocrinol. 30:65-75.

Cherrington, A. D. 1999. Banting lecture 1997. Control of glucose uptake and release by the liver in vivo. Diabetes 48:1198-1214.

Chomczynski, P., and N. Sacchi. 1987. Single-step method of RNA isolation by acid guanidinium thiocyanate-phenol-chloroform extraction. Anal. Biochem. 162:156-159.

Cochran, R. C., D. C. Adams, J. D. Wallace, and M. L. Galyean. 1986. Predicting digestibility of different diets with internal markers: Evaluation of four potential markers. J. Anim. Sci. 63:1476-1483.

Correa, C. E., R. D. Shaver, M. N. Pereira, J. G. Lauer, and K. Kohn. 2002. Relationship between corn vitreousness and ruminal in situ starch degradability. J. Dairy Sci. 85:3008-3012.

Goering, H. K., and P. J. Van Soest. 1970. Forage Fiber Analysis (Apparatus, Reagents, Procedures, and Some Applications). Agric. Handbook No. 379. ARS-USDA, Washington, DC.

Hach, C. C., B. K. Bowden, A. B. Lopelove, and S. V. Brayton. 1987. More powerful peroxide Kjeldahl digestion method. J. AOAC 70:783-787.

Harvatine, K. J., and M. S. Allen. 2006. Effects of fatty acid supplements on milk yield and energy balance of lactating dairy cows. J. Dairy Sci. 89:1081-1091.

Huntington, G. B. 1997. Starch utilization by ruminants: From basics to the bunk. J. Anim. Sci. 75:852-867.

Illius, A. W., B. J. Tolkamp, and J. Yearsley. 2002. The evolution of the control of food intake. Proc. Nutr. Soc. 61:465-472.

Karkalas, J. 1985. An improved enzymatic method for the determination of native and modified starch. J. Sci. Food Agric. 36:10191027.

Knowlton, K. F., B. P. Glenn, and R. A. Erdman. 1998. Performance, ruminal fermentation, and site of starch digestion in early lactation cows fed corn grain harvested and processed differently. J. Dairy Sci. 81:1972-1984.

Kotarski, S. F., R. D. Waniska, and K. K. Thurn. 1992. Starch hydrolysis by the ruminal microflora. J. Nutr. 122:178-190.
McCarthy, R. D., Jr., T. H. Klusmeyer, J. L. Vicini, J. H. Clark, and D. R. Nelson. 1989. Effects of source of protein and carbohydrate on ruminal fermentation and passage of nutrients to the small intestine of lactating cows. J. Dairy Sci. 72:2002-2016.

Meikle, A., M. Kulcsar, Y. Chilliard, H. Febel, C. Delavaud, D. Cavestany, and P. Chilibroste. 2004. Effects of parity and body condition at parturition on endocrine and reproductive parameters of the cow. Reproduction 127:727-737.

NRC. 2001. Nutrient Requirements of Dairy Cattle. 7th rev. ed. Natl. Acad. Sci., Washington, DC.

Oba, M., and M. S. Allen. 2000. Effects of brown midrib 3 mutation in corn silage on productivity of dairy cows fed two concentrations of dietary neutral detergent fiber: 1 . Feeding behavior and nutrient utilization. J. Dairy Sci. 83:1333-1341.

Oba, M., and M. S. Allen. 2003a. Effects of corn grain conservation method on feeding behavior and productivity of lactating dairy cows at two dietary starch concentrations. J. Dairy Sci. 86:174-183.

Oba, M., and M. S. Allen. 2003b. Effects of corn grain conservation method on ruminal digestion kinetics for lactating dairy cows at two dietary starch concentrations. J. Dairy Sci. 86:184-194.

Oba, M., and M. S. Allen. 2003c. Extent of hypophagia caused by propionate infusion is related to plasma glucose concentration in lactating dairy cows. J. Nutr. 133:1105-1112.

Oba, M., and M. S. Allen. 2003d. Intraruminal infusion of propionate alters feeding behavior and decreases energy intake of lactating dairy cows. J. Nutr. 133:1094-1099.

Polonsky, K. S., B. D. Given, L. Hirsch, E. T. Shapiro, H. Tillil, C Beebe, J. A. Galloway, B. H. Frank, T. Karrison, and E. Van Cauter. 1988. Quantitative study of insulin secretion and clearance in normal and obese subjects. J. Clin. Invest. 81:435-441.

Van Soest, P. J., J. B. Robertson, and B. A. Lewis. 1991. Methods for dietary fiber, neutral detergent fiber, and nonstarch polysaccharides in relation to animal nutrition. J. Dairy Sci. 74:35833597.

Vandesompele, J., K. De Preter, F. Pattyn, B. Poppe, N. Van Roy, A. De Paepe, and F. Speleman. 2002. Accurate normalization of real-time quantitative RT-PCR data by geometric averaging of multiple internal control genes. Genome Biol. 3:RESEARCH0034. (E-pub)

Whelan, J. A., N. B. Russell, and M. A. Whelan. 2003. A method for the absolute quantification of cDNA using real-time PCR. J. Immunol. Methods 278:261-269.

Wildman, E. E., G. M. Jones, P. E. Wagner, R. L. Boman, H. F. Troutt Jr., and T. N. Lesch. 1982. A dairy cow body condition scoring system and its relationship to selected production characteristics. J. Dairy Sci. 65:495-501.

Ying, Y., M. S. Allen, M. J. VandeHaar, and N. K. Ames. 1998. Effects of fineness of grinding and conservation method of corn grain on ruminal and whole tract digestibility and ruminal microbial protein production of Holstein cows in early lactation. J. Dairy Sci. 81(Suppl. 1):339. (Abstr.) 